\title{
“3 R” Approach of Market-Mechanism.”
}

\author{
Dr. Devadatta Ranade \\ P.S.College -Pune University, Maharashtra-India .
}

JEL-M-31, L-10, L-19

KEYWORDS-Mix, Rationality of Product Life Cycle, Users' Life Span, Reliability, Ring

\section{Introduction}

Global markets have changed entire scenario of marketing of products, services and even ideas about concepts of all traditional thinking. To make customers feel that the products are satisfying their needs and wants." is the aim of launching the products in market. Theories much rely upon the point of view of manufacturers, though it has been said that the marketing mix concept expresses independence of production, market and consumer/user. Consideration of consumers, more precisely, users, is not much weighted as a simultaneous part of marketing mix activities.

The initial 4 P's (Product, Price, Place and Promotion) along with the additional 3 P's (People, Process, Physical Evidence), no doubt, played an important role in establishing the marketing machinery concept useful and practical for global enterprises. Moreover, 4 C's (Customer solution, Customer cost, Customer convenience, Customer communication) also consider about the aspect of consumers. These approaches stressed prime consideration to marketer and secondary consideration to user.

Considering the mix elements, 3 R-conceptual theories can be a new approach in addition to the previous, which simultaneously emphasizes consideration of both factors of market as Manufacturer/Marketer and Customer/User. "3 R" . Theory develops this concept with equal balance between manufacturer/marketer and user as combined part of market mechanism. Considering marketing mix -Simultaneous Thinking -about "Marketers \& Users"- should be developed as two sides of a single coin for coping up with modern marketing mix in global scenario. There are " $3 \mathrm{R}$ " $\mathrm{s}$ to be considerd as a conceptual theory as-

\section{Rationality Of Life- Span Concept}

Rationality concept of life span is traditionally used as a prime concept in the field of marking. Product manufacturing and selling is based on the life cycle of the product, which is established as a base of diversification and/or innovation of product for particular period of time after launching the product in the market. The decline stage of existing product automatically gives rise to launching stage of new modern product as the manufacturer always wants to maintain his share in market as constant or rising share.

This considers both -Product Life Cycle as well as Users' Life-Span. At this point, it should be noted that concept of Product Life Cycle (PLC) is a tool that applies to an individual mark, but a generic product category (cars, televisions, microprocessors, etc) (Luo).

Users' Life Span (ULS) is the psychological period of time for decisive purchasing of a particular product. When the time span of both -the product and the users -matches each other, then only the decision of purchasing a particular product will be materialized.

Therefore, one of the crucial tasks that marketers require to perform is-"To identify the stage that is going through the generic category of the product."

Then he has to plan what will be done to address the risks posed by each stage, while taking advantage of the opportunities offered. At the same time, the decision of user to purchase must be kept intact. As there are various new innovative products, there is a time lag between thinking and execution. This can be called as Users' Life Span. When the user considers purchasing, it is not possible that he immediately purchases the product.

When he actually purchases the product, it may happen that he may purchase some other product than the previous one. Ultimately the users' life span of purchasing the product expires during the time lag of decision and execution. Life span is the key factor which must be considered within the limitations of PLC and ULS.

When the product begins to be accepted in the market it begins to grow sales and profits also. This is because the manufacturing costs per unit are reduced, either by increased production experience or by a greater production volume (Karniouchina, Uslay \& Erenburg). 
The product life cycle is a concept of great importance in the process of marketing any product, because the behavior of the market situation and competitive environment change over time in which the product is marketed. These changes affect the development of marketing strategy. Every product has a biological evolution as embodied in a series of sequential steps (Luan \& Sudhir). Similarly each user has own psychological time limit to be associated with the decision of buying a particular product.

The Product Life Cycle is time path that runs from product launching in market until it disappears from market. The Users' Life Span is also time path that runs from an idea to purchase a particular product until he really pays an amount to purchase the same.

The life cycle stages are classified into 4 sections: Introduction, Growth, Maturity and Decline. The life span of user also has 4 sections: Idea, Thinking, Decision and Purchasing. The life span of a product class is the longer, while the mark is shortest.

What characterizes the life span is the evolution of sales and profits, rising at first, gradually decreasing thereafter. The duration of the phases of the life span is not stable. The adoption process, which sets the tone for the early stages of product life span, can be altered by the emergence of new alternative products, consumer habits and marketing strategies followed by firms competing in the market .Furthermore, it has been found that the behavior of the sales of the most recent innovations shows a progressive shortening of the life span, particularly of the phases of growth and product introduction.

Quality improvement may increase the duration, reliability or security product or the consumer durable nutrient capacity, etc (Corstjens, Umbljis \& Wang). But an increase in quality is, generally, an increase of cost that the consumer is only willing to pay if he receives or product improvement is more demanding and appreciates quality. An improvement in the characteristics or performance of the product increases its usefulness, performance, safety or comfort. The change in product design or style of product enhances its appeal.

Among the strategies focused on changing patterns of market behavior according to marketer fit the following:

1. Promote increased use of the product among the regulars,

2. Develop a more varied use of the product among the most frequent users,

3. Create new users of the product to expand the market,

4. Finding new uses for the commodity (Möller).

Similarly, this strategy, as a part of users' aspect, should be considered along with -

1. Develop an idea about the requirement of the product in users' mind.

2. Motivate thinking process about the utility and necessitate of the product.

3. Psychological preparation of confirming buying decision of the same. .

4. Availability of the product within the geographical and economic reach.

When we say a product is in its growth stage or another, we are referring implicitly to its link with a particular market. That is, a product can receive a good acceptance (growth stage or maturity) in some markets but found in the introduction stage in others. Thus, microwave ovens were in the stage of maturity in the markets of airline catering and in plants, although they were still at the stage of introduction in almost all consumer markets.

In short, the product life cycle and users' life span are the set of stages (Introduction, Growth, Maturity and Decline as well as (Idea, Thinking, Decision and Purchasing) being experienced by a generic category of products, and whose concepts are used as a tool of marketing to know and track the stage where there is a particular product, in order, to identify in advance the risks and opportunities of each stage to a particular brand A key to successfully managing the Life Span is:

1) Predict how the proposed span of the product even before it is introduced and then, at each stage, and Generate the awareness in users about buying the products as soon as they are launched.

2) Provide for the needs of marketing in the next step and motivate the users to feel necessitates of the products with a feel of need and pride satisfying their psychology.

\section{Reality Of Product- Look}

Look is not just the form but all that the product that we perceive through the senses. Appearance is all it is only in certain products is a disaster and in others it is very well made. Well taken into account in every detail. That's the difference. Look is present in any product.

The anthropometry is the study of human dimensions. Look differs from customer to customer as per his own perceptions. Studying user-specific percentiles of your product, you can get the human dimensions mean a statistically average customer of its potential.

The appearance must be one of the most used as an excuse to sell, as a sales tool, especially for marketers. The appearance is mentioned, despite being so absent in the products.

Very few people in the scene of the design are clear about what is appearance. Mention it, promote it, revere it, but do not know. (Osinga, Leeflang \& Wieringa) 
Some examples include: Consider the size of the hands of people in certain age bans to design a cell phone (Fischer \& Albers). Define visual field location of windows and decorated in a shop. Dimensions of users to evaluate the design of transport vehicles. There are many possibilities. Find out in technical libraries, where books get specific topic. Make sure the models taken as a reference in the literature models are appropriate to their users.

It includes a comprehensive analysis, looking at the historical evolution of the product and the study of the current trend of fashion and styles present in the market.

Evaluate the type of shape, if laminar or linear volume is also important. Defines use situations. Based on these usage scenarios, decide if there are problems caused by the volume or the distribution of volumes in the studied object.

Look relates with psychological mind set up activities of user, till he confirms the particular product to be purchased and converts his decision into reality of buying the same. In addition to utility of the product, look $\&$ get-up of the product, attracts the minds of the customer. This makes them buy a particular product instead of other one. The perception of different classes \& segments of users are absolutely different . This is key factor in modern mix. Reality of look can be judged on the basis culture, perceptions, attitudes and liking s of customers The ideology of the customers are different on the basis of their segments which are unpredictable. Look is a thing which differs from region to region, man to man, caste to caste, habits to habits, and so on.

It is the prime responsibility of the manufactures that customers throughout globe should feel that product they are going to purchase is according to their imagination of look and gives them satisfaction of the look; they have kept in kind for purchase of particular product, e.g. Africans can be attracted towards white beauty whereas Americans can be attracted towards black beauty.

This is not racial or classical approach. A principal of adverse attraction is applied here for demand of products in different regions which should be considered by the manufactures.

\section{Ring Of Logistics}

The word "Ring" indicates the entire system of Logistic. Logistic has many aspects of a chain right from the manufactures to the hands of end user/customer.

As the industrial combinations do use the words as -Ring, Pools, and Cartels for describing their forms of organizations, "Ring" has been used in the same sense that logistic is a part of operations of transferring good from manufacturer to customers. This operation requires a chain or ring of organizations and man power for proper transfers of goods and products. Therefore this logistic concept is called as -"Ring of logistic." This can be viewed as under which helps both the marketer and user.

There are various ways and Medias of transformation of products in the hands of users through new and innovative marketing Medias of providing products and ideas.

A distributor of products should have geographically distributed warehouses so as to meet the demand of each consumer centers must provide (Luan \& Sudhir). The distance between the centers of consumption with wineries and distance distribution of these to the central warehouse, somehow determine system performance and costs thereof.

The organization need to have a tool to evaluate alternatives to size and locate distribution warehouses in a given geographical area.

The completion of the work will involve formulating the problem, considering the service quality indicators relevant to monitor. Perform the logical model of the simulator, build the physical model, operate and eventually obtain and analyze the results. The logistic flow has a number of activities to be met, as quickly as possible to meet customer needs (Constantinides). First, the producer must require a warehouse or factory, buy raw materials to the respective vendors and then convert them into finished products. Once completed this process, products are sold to distributors, who are responsible for storing and transporting them to the point of sale. Finally, commercial establishments will work to buy that good, put it in the stands and sell to final consumers.

Just the logistics mission is to place the products following the appropriate parameters of quality and quantity, in order to avoid shortages. However, the problem arises when introduced into the market in resource abundance. The idea is to compensate for this with the greatest possible economy. Avoid complicated processes when producing and distributing the product, the simplicity in the planning of logistics activities is ideal (Ataman, Heerde \& Mela). Also, the logistics system must be able to adapt to different circumstances, to changing situations, hence they require flexibility.

The organization must also properly coordinate the many diverse activities that integrate, in order to meet market demands immediately. The logistics functions as a cycle in which the producer, distributor and end user up a gear indestructible. If any of them missing, the logistics flow is broken. This is precisely what we must avoid. 
Its function is to optimize freight, make sure the products are transported in a good way to calculate waiting times and discharge, handling and storage control. The ultimate goal is to reduce logistics inventory levels and optimize the performance of the entire supply chain. In our country, recently companies are finding the importance of logistics (Osinga, Leeflang \& Wieringa).

Not only as a competitive strategy, reduce costs and, most importantly, to give excellent customer service, all at reasonable costs. It is important that companies consider our environment for logistics as an integral part of their plans due to issues such as, Customer service and satisfaction, as this aspect should be the cornerstone of marketing strategies. Exposure of the concepts behind the logistic function is a journey throughout the supply chain (service level, order cycle, distribution, storage, manufacture, procurement, purchasing, etc.) (Lehtinen).

On the other hand, developing strategic logistics structure needed to achieve the ultimate goals of increasing customer satisfaction, support services and post sales customer, reduce the time lag between ordering and delivery of goods and products, reduce overall costs, increase the quality of the delivery process, reach strategic agreements with customers, carriers, logistics providers and suppliers, using information technologies and improve, with all this, the company's competitive position.

Another aspect to be considered as something of vital importance in regard to logistics is the Inventory Management. After defining the prices, the ability to maximize profits in the business for the various participants in the chain, is given by the adjustments in operating costs, and that is where it is necessary to efficiently manage the number and variety of products ie Inventory Management is one of the keys to business success (Constantinides). Inventory management is one of the determining factors in the chain supplier distributor - consumer.

The professionalization of business, inventory reduction, cost, development time, delivery, and increased service levels are just some of the many benefits that this scheme can give a company. Obviously avoid losing sales because of lack of goods, which happens too in most Bolivian companies also from the financial point of view, makes better use of funds, freeing up resources for other areas of the organization (Corstjens, Umbljis \& Wang). The Competitive Logistics contributes directly to achieving high levels of customer service and low costs.

The logistics concept is applied in enterprises characterized by playing an integral role in the activities that are related to flow assurance aimed at providing the customer with products and services required at the time that demand, with the quality required and the cost you organization are willing to pay. This does not mean that management logistics management assume each of the above activities, it takes care of coordinating the variables of each to ensure solutions perform according to a rational flow and ensure a high level of customer service with low costs (Möller).. The company must adopt for this purpose a management philosophy and a flat organizational units or network that enables a consistent application of this concept organizational logistics.

\section{Works Cited}

[1]. Brooks, Neil, and Lyndon Simkin. "Measuring Marketing Effectiveness: An Agenda For Smes." Marketing Review 11.1 (2011): 324. Brooks, Neil, and Lyndon Simkin. "Measuring Marketing Effectiveness: An Agenda For Smes." Marketing Review 11.1 (2011): 3-24.

[2]. Constantinides, E. "The Marketing Mix Revisited: Towards The 21St Century Marketing." Journal Of Marketing Management 22.3/4 (2006): 407-438.

[3]. Corstjens, Marcel, Andris Umbljis, and Chao Wang. "The Power Of Inertia." Journal Of Advertising Research 51.2 (2011): 356372 .

[4]. Hanssens, Dominique M. "Advertising Impact Generalizations In A Marketing Mix Context." Journal Of Advertising Research 49.2 (2009): 127-129.

[5]. Karniouchina, Ekaterina V, Can Uslay, and Grigori Erenburg. "Do Marketing Media Have Life Cycles? The Case Of Product Placement In Movies." Journal Of Marketing 75.3 (2011): 27-48.

[6]. Laszlo Tihanyi, et al. "Where Is The Opportunity Without The Customer? An Integration Of Marketing Activities, The Entrepreneurship Process, And Institutional Theory." Journal Of The Academy Of Marketing Science 39.4 (2011): $537-554$.

[7]. Lehtinen, Uolevi. "Combining Mix And Relationship Marketing." Marketing Review 11.2 (2011): 117-136.

[8]. Luan, Y. Jackie, and K Sudhir. "Forecasting Marketing-Mix Responsiveness For New Products."Journal Of Marketing Research (JMR) 47.3 (2010): 444-457.

[9]. Luo, Lan. "Product Line Design For Consumer Durables: An Integrated Marketing And Engineering Approach." Journal Of Marketing Research (JMR) 48.1 (2011): 128-139.

[10]. Marnik G Dekimpe, et al. "The Effect Of Business-Cycle Fluctuations On Private-Label Share: What Has Marketing Conduct Got To Do With It??." Journal Of Marketing 76.1 (2012): 1-19.

[11]. Möller, Kristian. "Marketing Mix Discussion - Is The Mix Misleading Us Or Are We Misreading The Mix?." Journal Of Marketing Management 22.3/4 (2006): 439-450.

[12]. Osinga, Ernst C, Peter S.H Leeflang, and Jaap E Wieringa. "Early Marketing Matters: A Time-Varying Parameter Approach To Persistence Modeling." Journal Of Marketing Research (JMR) 47.1 (2010): 173-185.

[13]. Yu-Jia, Hu. "How Brand Equity, Marketing Mix Strategy And Service Quality Affect Customer Loyalty: The Case Of Retail Chain Stores In Taiwan." International Journal Of Organizational Innovation 4.1 (2011): 59-73. 